\title{
Аноды для литий-ионных аккумуляторов на основе $p$-Si с самоорганизующимися макропорами
}

\author{
(C) Н.Е. Преображенский, Е.В. Астрова, С.И. Павлов, В.Б. Воронков, А.М. Румянцев, В.В. Жданов \\ Физико-технический институт им. А.Ф. Иофрфе Российской академии наук, \\ 194021 Санкт-Петербург, Россия \\ ฯ E-mail: npsoft86@gmail.com
}

(Получена 10 мая 2016 г. Принята к печати 18 мая 2016 г.)

\begin{abstract}
Практическое применение технологии электрохимического травления монокристаллического кремния для изготовления микроструктурированных анодов сдерживает их себестоимость. Предлагаемый подход позволит сократить издержки за счет: снижения требований к качеству исходного материала путем замены $n$-Si на $p$ - $\mathrm{Si}$, исключения операций по формированию затравочных центров и многократного использования кремниевой подложки. В работе проведены исследования процесса образования неупорядоченных макропор в $p-\mathrm{Si}(100)$ с удельным сопротивлением 10-20 Ом - см в 4\%-м растворе плавиковой кислоты в диметилформамиде и определен вклад в него химического растворения кремния. Получены зависимости от плотности тока для скорости анодирования, морфологии пористых слоев, эффективной валентности, числа пор на единицу поверхности и средних значений диаметра пор. Разработана технология формирования пористых слоев толщиной $\sim 50$ мкм и пористостью $\sim 70 \%$, сочетающая возможность последовательного отделения нескольких мембран от одной и той же подложки. Исследованы электрохимические характеристики анодов, изготовленных из этих мембран, и проведено $120+$ циклов испытаний при токе заряда/разряда $0.2 \mathrm{~A} / \Gamma$ в режиме ограничения зарядной емкости величиной 1000 мА · ч/г.
\end{abstract}

DOI: $10.21883 /$ FTP.2017.01.44000.8314

\section{1. Введение}

Макропористый кремний является перспективным материалом для анодов литий-ионных аккумуляторов нового поколения [1-3]. Аноды, изготовленные с помощью электрохимического травления пластин монокристаллического кремния, имеют высокую удельную емкость, средние скорости заряда и, при правильно выбранных геометрических параметрах структуры и режима циклических испытаний, высокую устойчивость к деградации $[4,5]$. Периодические структуры в виде тонких монокристаллических плоскостей кремния, организованных в трехмерную решетку в виде сетки или зигзагообразных вертикальных стенок, послужили удачным модельным объектом для исследования процессов циклического литирования/делитирования и позволили определить оптимальные размеры и кристаллографическую ориентацию составляющих их элементов, а также максимальное количество внедряемого лития, при котором можно избежать быстрого разрушения анода [6,7]. На основе полученных данных нами была разработана технология изготовления анодов с регулярной решеткой на $n-\mathrm{Si}$, включающая в себя создание затравочных ямок с помощью фотолитографии, фотоанодирование в водном растворе HF, отделение мембраны от подложки, последующую обработку в растворе $\mathrm{KOH}$ (шейпинг макропор) и формирование токоведущего медного контакта [8]. Изготовление макропористых слоев и мембран на $n$-Si c помощью анодирования в условиях подсветки обратной стороны пластины [9] предъявляет высокие требования ко времени жизни неосновных носителей заряда (дырок). Поэтому использование дырочного кремния, где дырки являются основными носителями, снимает это ограничение. Определенным препятствием на пути практического применения кремниевых макропористых анодов является их высокая себестоимость, в которую входят затраты на изготовление и цена исходного материала. Исключение нескольких технологических операций по созданию упорядоченных затравочных центров на поверхности пластин позволит снизить издержки на изготовление. Сушественным фактором является экономия исходного монокристаллического кремния. Как показали наши эксперименты, толщина активно работающего слоя анодного материала составляет 20-50 мкм [10], а стандартные кремниевые пластины диаметром 76-100 мм имеют толщину 380-560 мкм, т.е. из одной пластины можно получить несколько мембран.

Целью настоящей работы явилась разработка более простой и дешевой технологии получения макропористых анодов за счет использования $p$ - $\mathrm{Si}$, самоорганизующихся макропор и отделения нескольких мембран от одной и той же пластины.

\section{2. Макропоры в $p$-Si}

Образование макропор в дырочном кремнии менее изучено, чем в электронном. Современное состояние вопроса и предложенные модели отражены в работах [11-13]. Макропоры в $p-\mathrm{Si}$ можно получить как в водных, так и в органических электролитах, содержащих плавиковую кислоту (HF): диметилформамиде (ДМФ), пропиленкарбонате, диметилсульфоксиде, ацетонитриле. Известно, что образование макропор возможно только в достаточно высокоомных подложках. Пороговое значение удельного сопротивления дырочного кремния, ниже 

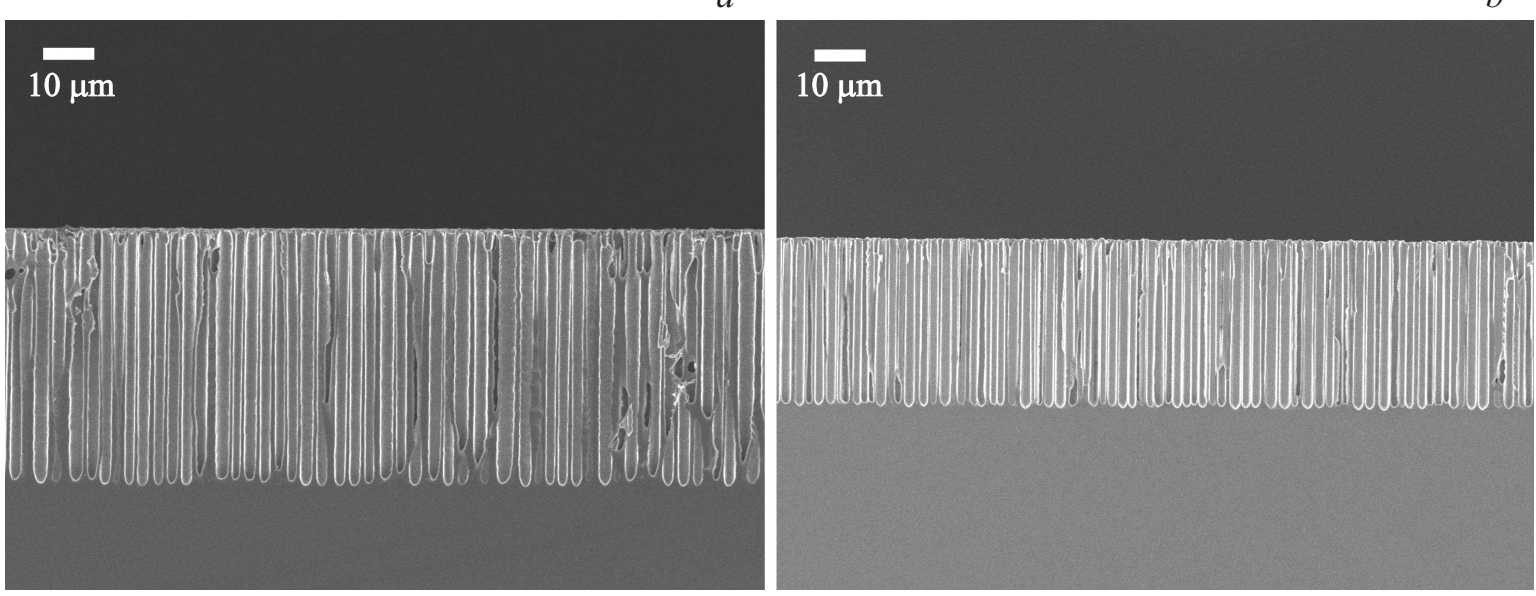

Рис. 1. SЕМ-микрофотографии поперечного сечения образцов после анодирования при $j=2 \mathrm{MA} / \mathrm{cm}^{2}, t=360$ мин $(a)$ и $j=16 \mathrm{MA} / \mathrm{cm}^{2}, t=45$ мин $(b)$.
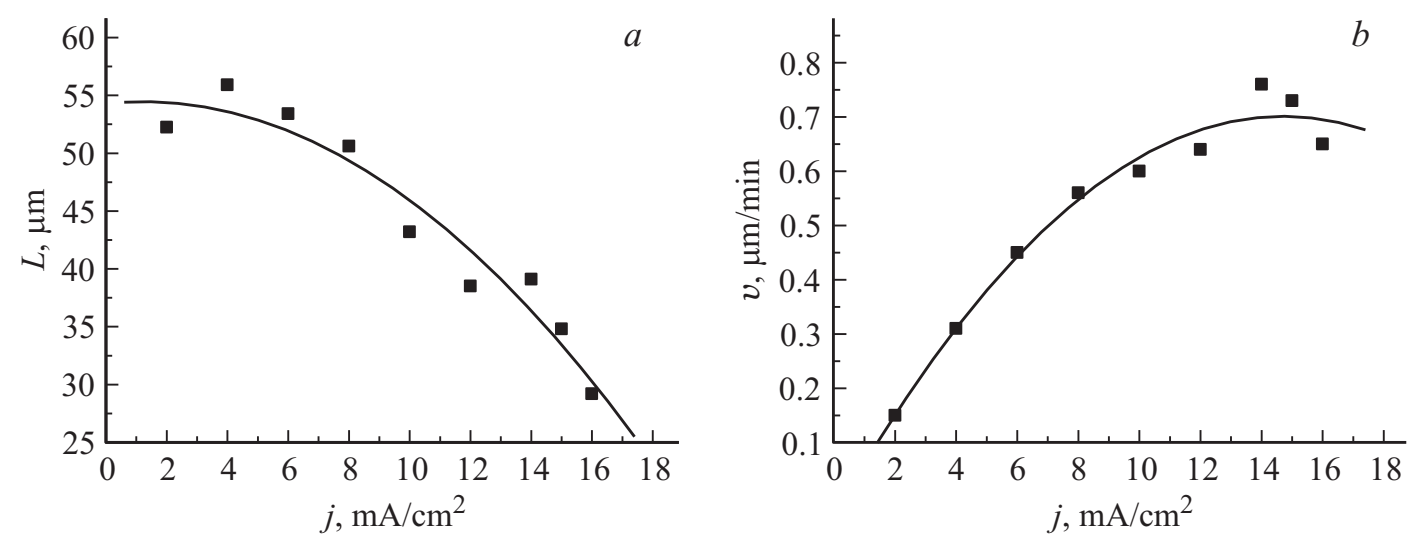

Рис. 2. Зависимость глубины макропор $(a)$ и скорости анодирования $(b)$ от плотности тока при электрохимическом травлении в режиме постоянного $Q_{\text {etch. }}$

которого макропоры не образуются, существенно ниже для апротонных органических электролитов, чем для водных, что означает более широкий диапазон уровней легирования подложки, пригодных для анодирования. В настоящей работе мы использовали анодирование в растворе 4\% по массе $\mathrm{HF}(48 \%$-й $)$ в ДМФ, обеспечивающем устойчивое образование макропор в кремнии среднего уровня легирования. Исходным материалом служил кремний, выращенный методом Чохральского, легированный бором, с удельным сопротивлением 10-20 Ом · см. Пластины диаметром 76 мм и толщиной 380-400 мкм, ориентированные в плоскости (100), имели одностороннюю полировку. Пластины разрезали на квадратные образцы со сторонами 25 мм вдоль направлений $\langle 110\rangle$. Для получения однородных по площади пористых слоев с обратной стороны образцов формировался $p^{+}$-слой путем ионной имплантации бора (доза $\left.8 \cdot 10^{15} \mathrm{~cm}^{-2}\right)$ и последующего отжига в атмосфере азота при $900^{\circ} \mathrm{C}$ в течение 20 мин.

Анодирование проводилось в гальваностатическом режиме на установке SiPor фирмы ET\&TE в однокамерной ячейке с постоянной прокачкой термостатированного при $22^{\circ} \mathrm{C}$ электролита. Диаметр анодируемой области составлял 20 мм. Электрохимическое травление проводили при разных плотностях тока и разной длительности процесса, но так, что количество электричества оставалось постоянным: $Q_{\text {etch }}=I t=135.6$ Кл, где $I$ ток, $t$ - время анодирования. Образцы взвешивали до и после анодирования (соответственно массы $m_{1}$ и $\left.m_{2}\right)$, затем раскалывали и измеряли глубину пор $L$ с помощью оптического микроскопа Nicon LV150. Для нахождения пористости $p$ использовался гравиметрический метод [14]:

$$
p=\frac{m_{1}-m_{2}}{\rho_{\mathrm{Si}} L S}
$$

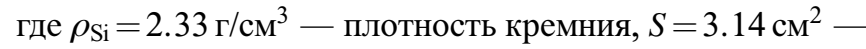
площадь пористой части образца. Следует отметить, что при выбранном режиме травления (постоянном $Q_{\text {etch }}$ ) глубина пор лежала в диапазоне 29-55 мкм, а изменение массы $m_{1}-m_{2}$ составляло $>14$ мг, что позволяло надежно регистрировать эту величину.

На рис. 1 приведены микрофотографии поперечных сколов, полученные в сканирующем электронном микро- 


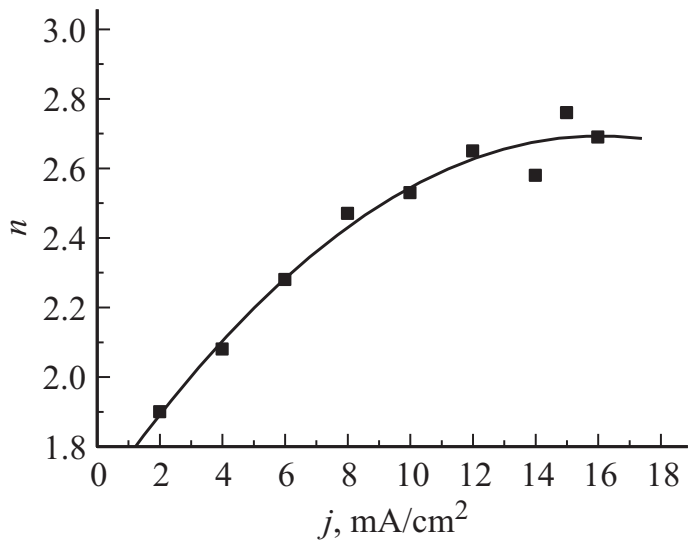

Рис. 3. Эффективная валентность как функция плотности тока анодирования.

скопе (SEM), из которых видно, что при всех значениях плотности тока образуются макропоры с вертикальными стенками и ровным фронтом. По мере возрастания плотности тока $j$ глубина пористого слоя уменьшается, а скорость травления $(v=L / t)$ стремится к насыщению (см. рис. 2).

Значение валентности растворения кремния $n$ определяли по закону Фарадея, из которого применительно к нашему случаю постоянного $Q_{\text {etch }}$ следует, что $n=39.46 /\left(m_{1}-m_{2}\right)$, где $m_{1,2}$ в мг. Из рис. 3 видно, что валентность возрастает с увеличением плотности тока и стремится к насыщению $(n=2.7)$. Эта величина близка к средней валентности, характерной для образования макропор в $n$-Si $(n=2.6)$, где на дне пор происходит электрополировка и $v \neq f(j)$ [9].

На рис. 4 показано, как изменяется форма и число случайных пор на единицу площади. По мере возрастания тока наблюдается постепенное увеличение плотности пор и уменьшение размера их поперечного сечения. Следует обратить внимание на то, что количество вымирающих пор, которые на рис. 4, $a$ видны как серые ямки, снижается. Наблюдаемый эффект связан с процессом самоорганизации затравочных центров, из которых поры либо развиваются, глубоко проникая в подложку, либо достаточно быстро вымирают. Также хорошо видно, что с ростом $j$ анизотропия скорости травления существен-
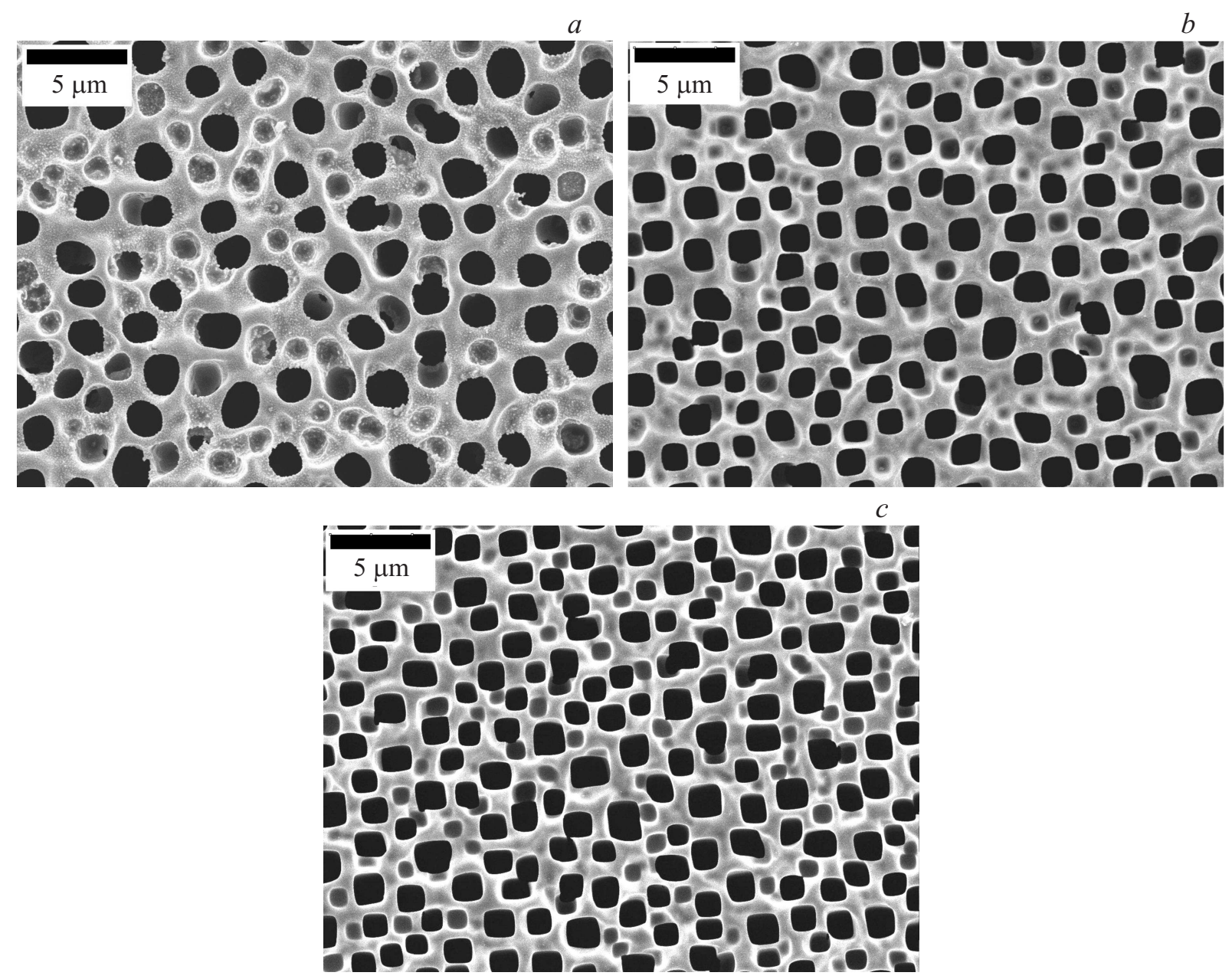

Рис. 4. SEM-микрофотографии макропор на лицевой поверхности образцов, анодированных при плотности тока: $2(a), 10(b)$, $16 \mathrm{MA} / \mathrm{cm}^{2}(c)$. 

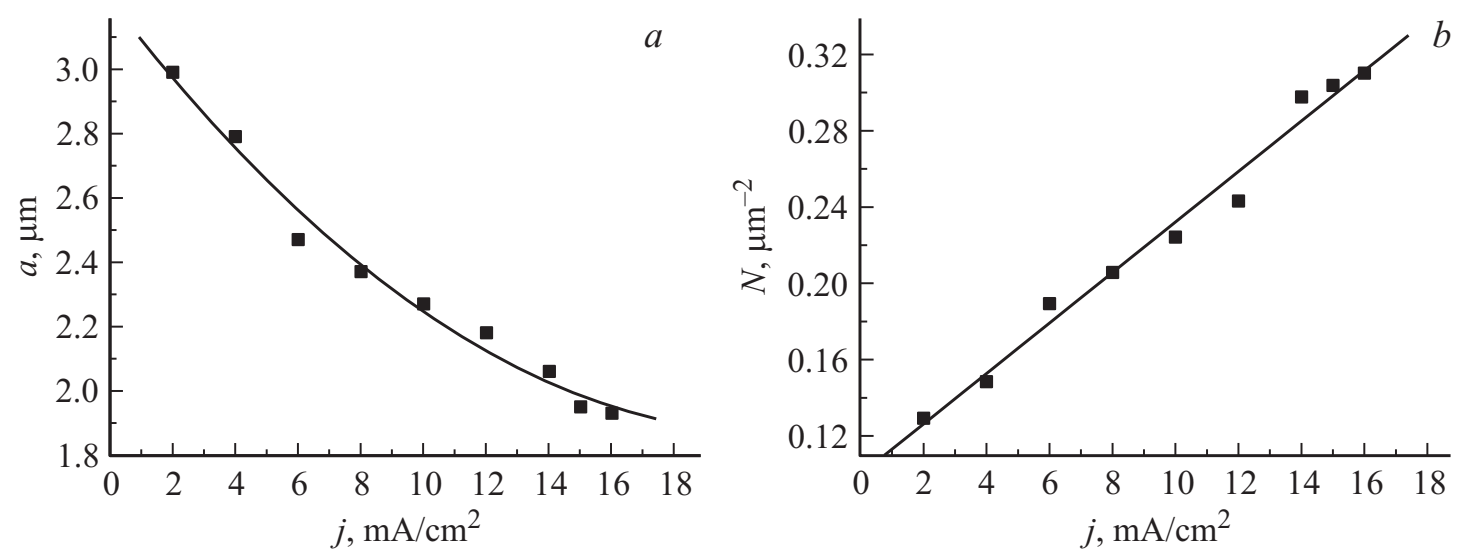

Рис. 5. Зависимость среднего расстояния между порами $(a)$ и числа пор на единицу площади $(b)$ от плотности тока анодирования.

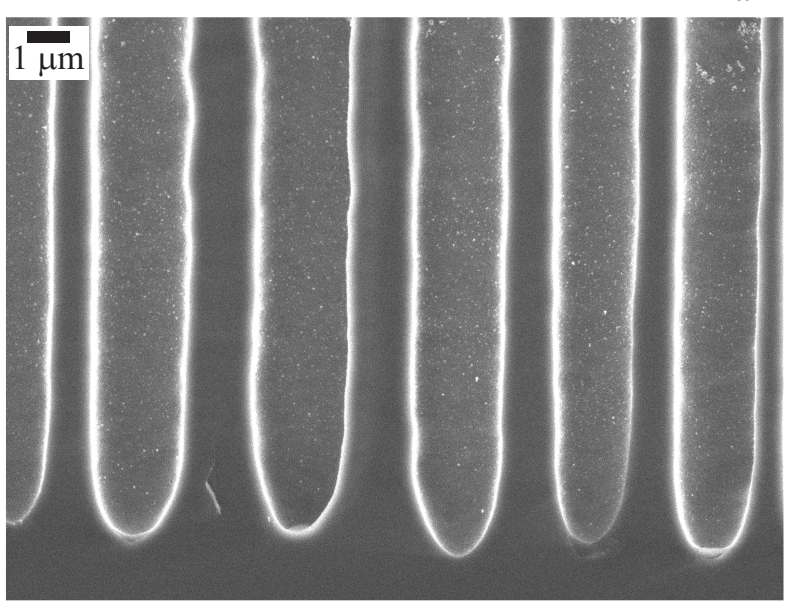

$b$

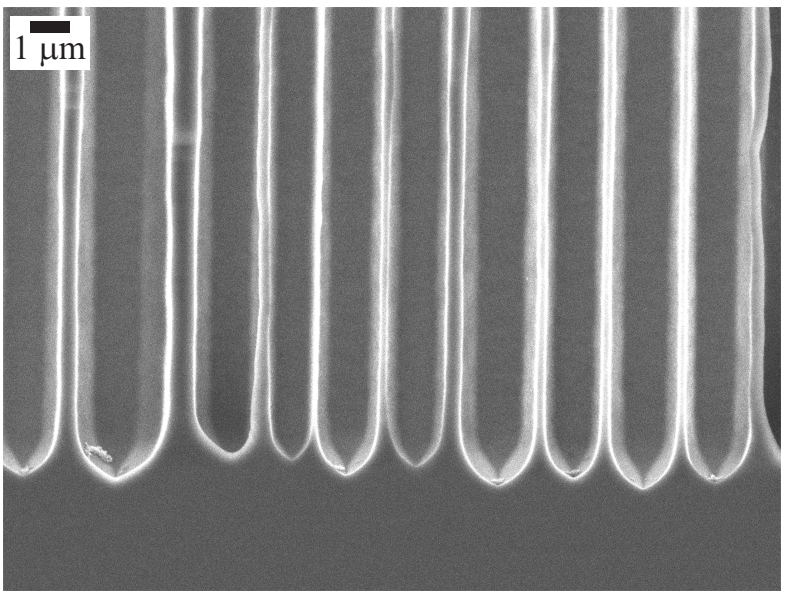

Рис. 6. SEM-микрофотографии нижней части пор в плоскости поперечного сечения (110) для макропористых слоев, полученных при плотности тока $2(a)$ и $16 \mathrm{~mA} / \mathrm{cm}^{2}(b)$.

но возрастает, что приводит к постепенному преобразованию круглого сечения в квадратное с закругленными углами. Преимущественное растворение происходит вдоль направления $\langle 100\rangle$ (рис. 4, c). Среднее расстояние между макропорами $a$ находили путем подсчета числа пор на единицу длины поперечного сечения в нижней части пористого слоя, чтобы избежать ошибки, связанной с вымиранием некоторых пор в приповерхностном нуклеационном слое. Плотность пор на единицу площади, $N$, рассчитывали из $а$ по формуле $N=1.155 / a^{2}$, учитывая, что поры образуют квазигексагональную решетку (см. далее). На рис. 5 показаны зависимости $a=f(j)$ и $N=f(j)$, из которых видно, что среднее расстояние между порами уменьшается, а плотность пор линейно возрастает с током анодирования.

По мере возрастания тока помимо модификации формы поперечного сечения происходят и другие изменения морфологии пор. На рис. 6 показана нижняя часть макропор, образующихся при малой и большой плотностях тока. Если в первом случае дно закругленное, то во втором видно острое донышко и фасетирование, кото- рое говорит об увеличении анизотропии. Угол между горизонтальной осью $\langle 110\rangle$ и стороной угла, образующего дно, составляет $35^{\circ}$, откуда следует, что огранка происходит медленно травящимися плоскостями (111). Рост валентности также свидетельствует об увеличении вклада процесса электрополировки. Усиление анизотропии обусловлено переходом от порообразования, при котором макропоры ориентируются вдоль линий тока (current oriented), к порам, ориентированным преимущественно вдоль определенного кристаллографического направления (crystal oriented) [11,12], в нашем случае $\langle 100\rangle$.

Зависимость, представленная на рис. 7, указывает на то, что в использованном нами режиме $Q_{\text {etch }}=$ const пористость по мере увеличения плотности тока изменяется немонотонно. Мы предположили, что это связано с химическим растворением кремния. Чтобы проверить, действительно ли увеличенная пористость при малых токах обусловлена длительной экспозицией в электролите, был проведен дополнительный эксперимент, при котором после анодирования при плотности тока 


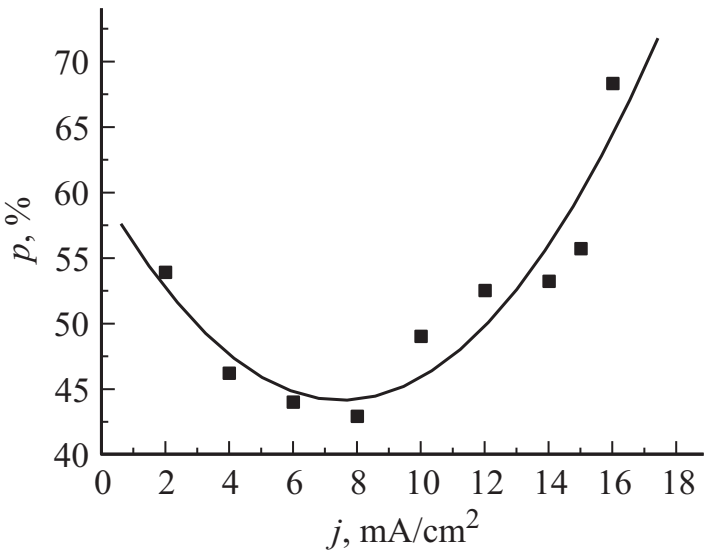

Рис. 7. Зависимость гравиметрической пористости от плотности тока.

$j=8 \mathrm{~mA} / \mathrm{cm}^{2}$ в течение 90 мин, образец дополнительно выдерживали в ячейке при сохраняющейся прокачке электролита. Сравнение параметров двух образцов приведено в табл. 1, из которой видно, что во втором случае глубина полученных пор и пористость возросли, а эффективная валентность снизилась. Последнее свидетельствует о том, что изменение массы образца частично обусловлено химическим растворением. Увеличение $L$ составило 6.4 мкм, что при делении на 387 мин дает 16.5 нм/мин. Эта величина характеризует скорость химического растворения кремния в $4 \%$-м растворе $\mathrm{HF}$ в ДМФ при комнатной температуре. Таким образом, при большой длительности анодирования вклад химического растворения приводит к увеличению пористости.

В литературе приводятся разные данные о том, как меняется диаметр макропор от плотности тока: в работе $[15]$ он оставался неизменным, в работах $[16,17]$ слегка уменьшался с ростом $j$. Оценим средний диаметр макропор $d$ из наших экспериментов. Его можно определить двумя способами: непосредственно измерить на изображении поперечного сечения $d_{\text {meas }}$ или вычислить из гравиметрической пористости, полагая, что сечение
Таблица 1. Влияние дополнительной экспозиции в течение 387 мин в 4\%-м растворе НF в ДМФ на параметры макропор, полученных при $j=8 \mathrm{MA} / \mathrm{cm}^{2}$ в течение 90 мин

\begin{tabular}{c|c|c}
\hline Параметр & Анодирование & $\begin{array}{c}\text { Анодирование + дополнительная } \\
\text { экспозиция в электролите }\end{array}$ \\
\hline$L$, мкм & 50.6 & 57.0 \\
$p, \%$ & 42.9 & 52.3 \\
$n$ & 2.47 & 1.79
\end{tabular}

пор круглое, $d_{\text {calc }}=1.05 a \sqrt{p}$. Среднюю толщину стенок в обоих случаях легко найти как $w=a-d$. Определяющим параметром микроструктурированных кремниевых анодов является толщина стенки, в которую литий должен продиффундировать насквозь в процессе заряда аккумулятора [6]. Поэтому для нас наибольший интерес в неупорядоченных структурах представляет средняя толщина кремниевых стенок. На рис. 8 приведены $d$ и $w$ в зависимости от плотности тока анодирования. Расчетные значения диаметра получились несколько выше, чем измеренные непосредственно, что, возможно, связано с завышенной пористостью (из-за небольшого заглубления пористой поверхности $\sim 2$ мкм) и отклонением сечения пор от круглой формы. Видно также, что диаметр макропор уменьшается по мере возрастания тока, стремясь к постоянной величине $\sim 1.56$ мкм. Соответствующие значения средней толщины стенок уменьшаются с ростом тока от $\sim 0.9$ до $\sim 0.3$ мкм. Таким образом, приходим к выводу, что основной причиной уменьшения толщины стенок является увеличение плотности пор.

\section{3. Макропористые мембраны}

Чтобы получить мембраны для анодных структур, использовались образцы размером $15 \times 15$ мм без $p^{+}$-контакта, диаметр анодируемой области в этих экспериментах составлял 10 мм. Электрохимическое трав-
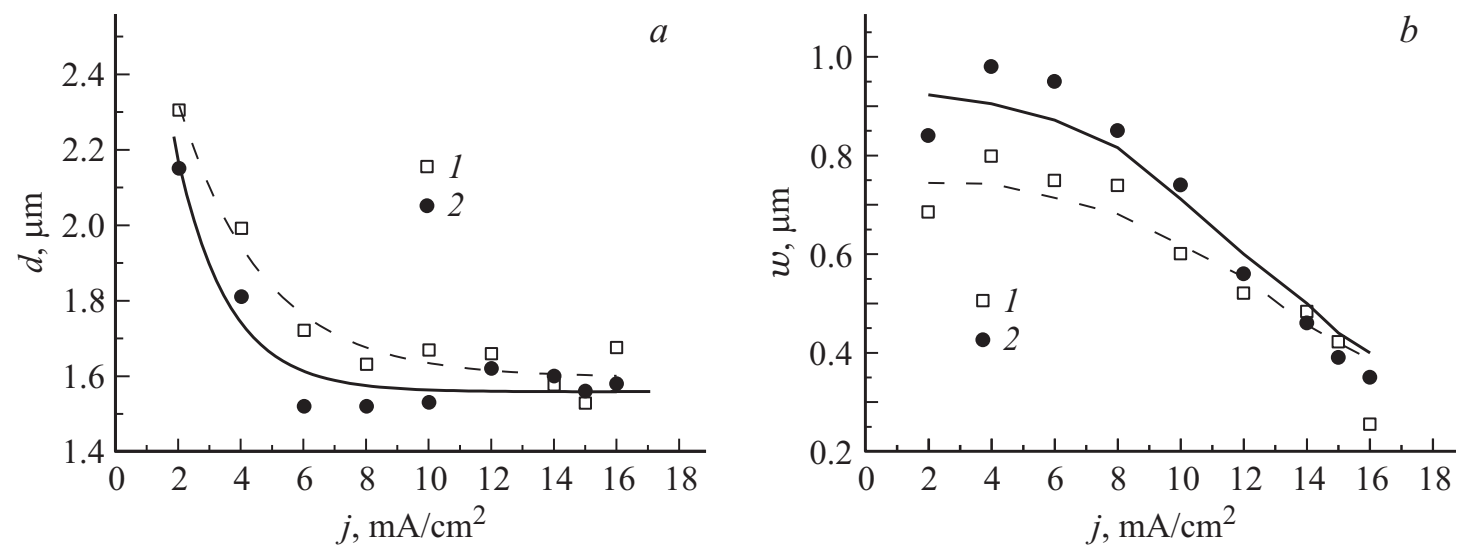

Рис. 8. Зависимость средних значений диаметра макропор $(a)$ и толщины стенок $(b)$ от плотности тока анодирования. Приведены величины: $a-d_{\text {calc }}(1), d_{\text {meas }}(2) ; b-$ соответствующие им значения $w(1,2)$. 


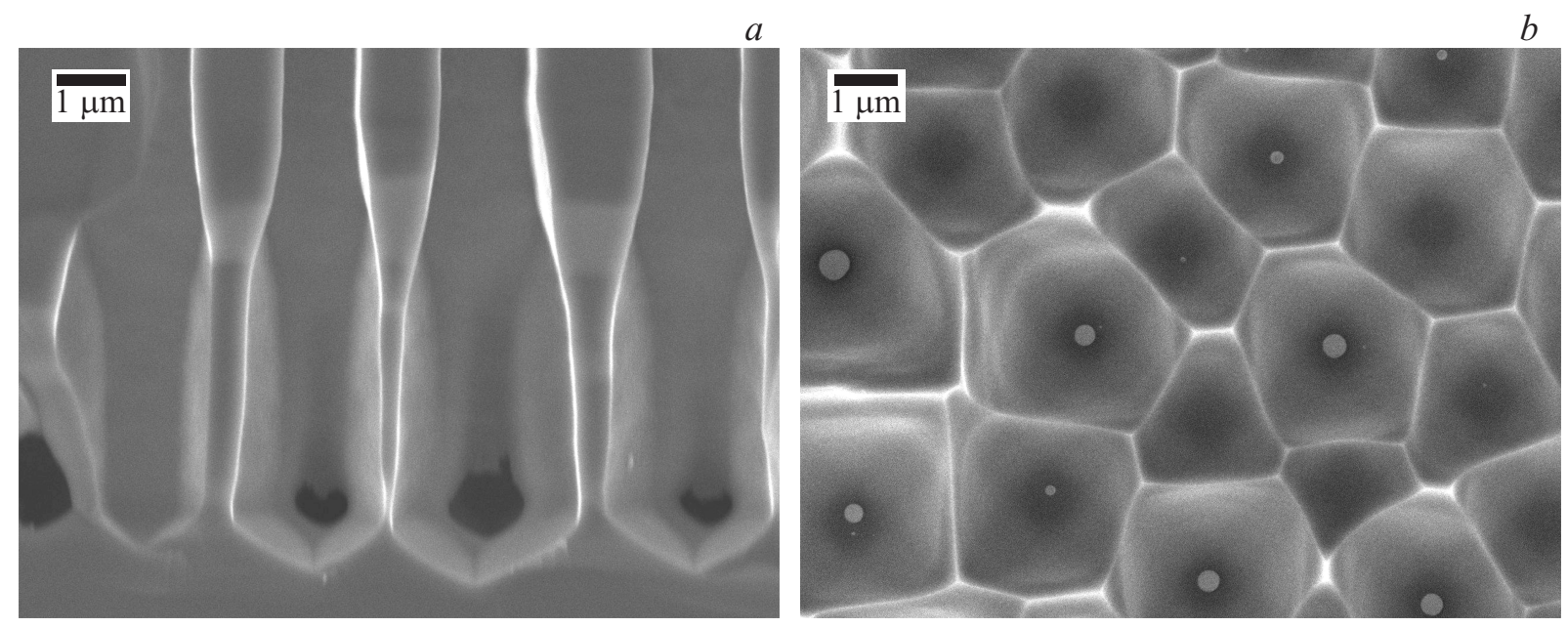

Рис. 9. Отделение пористого слоя от подложки: $a-$ нижняя часть макропор (поперечное сечение), $b-$ углубления, оставшиеся на подложке после отделения пористого слоя (вид сверху).
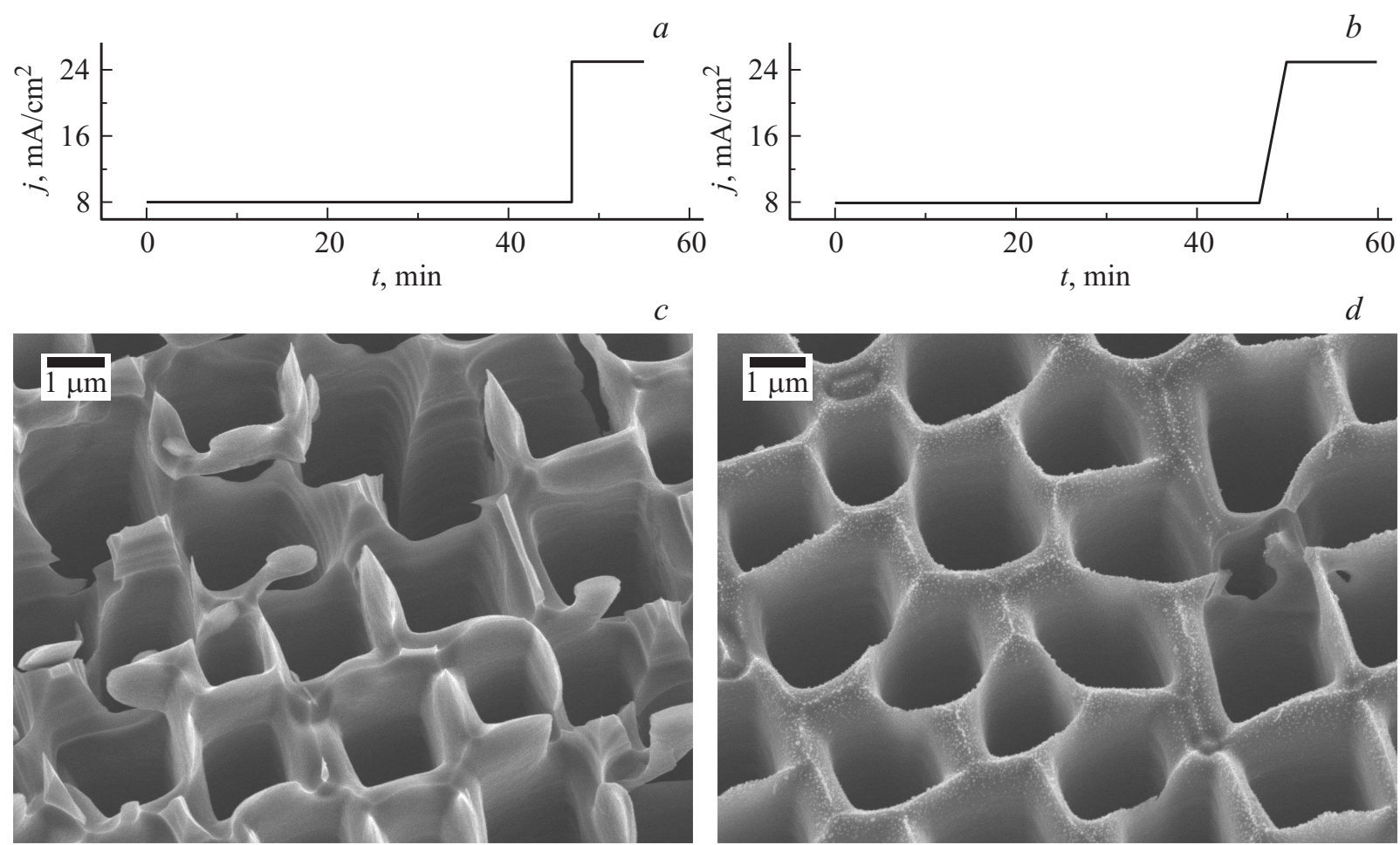

Рис. 10. Режимы анодирования $(a, b)$ и соответствующие им SEM-микрофотографии обратной стороны мембран $(c, d)$.

ление проводили в течение 45-90 мин при плотности тока $8 \mathrm{MA} / \mathrm{cm}^{2}$. Для отделения мембраны от подложки использовался известный прием по увеличению плотности тока в финальной фазе анодирования [18-20], в нашем случае 10 мин при $j=21-25 \mathrm{MA} / \mathrm{cm}^{2}$. При этом, как правило, достигается критическая плотность тока $j_{\mathrm{PS}}$, соответствующая переходу от режима порообразования к электрополировке. Как видно из рис. 9, $a$, в нижней части пористого слоя возрастает диаметр пор вплоть до смыкания соседних пор, в результате чего мембрана отделяется, а на подложке остаются углубления, которые служат затравочными центрами при повторном анодировании. Из рис. 9, $b$ хорошо видно, что каждое из углублений имеет шесть соседей, т. е. расположение макропор характеризуется квазигексагональной плотной упаковкой.

Нами были опробованы два режима увеличения тока: резкий (изменение тока во времени показано на рис. $10, a)$ и плавный, при котором плотность тока линейно нарастала в течение 5 мин (рис. 10,b). Как 


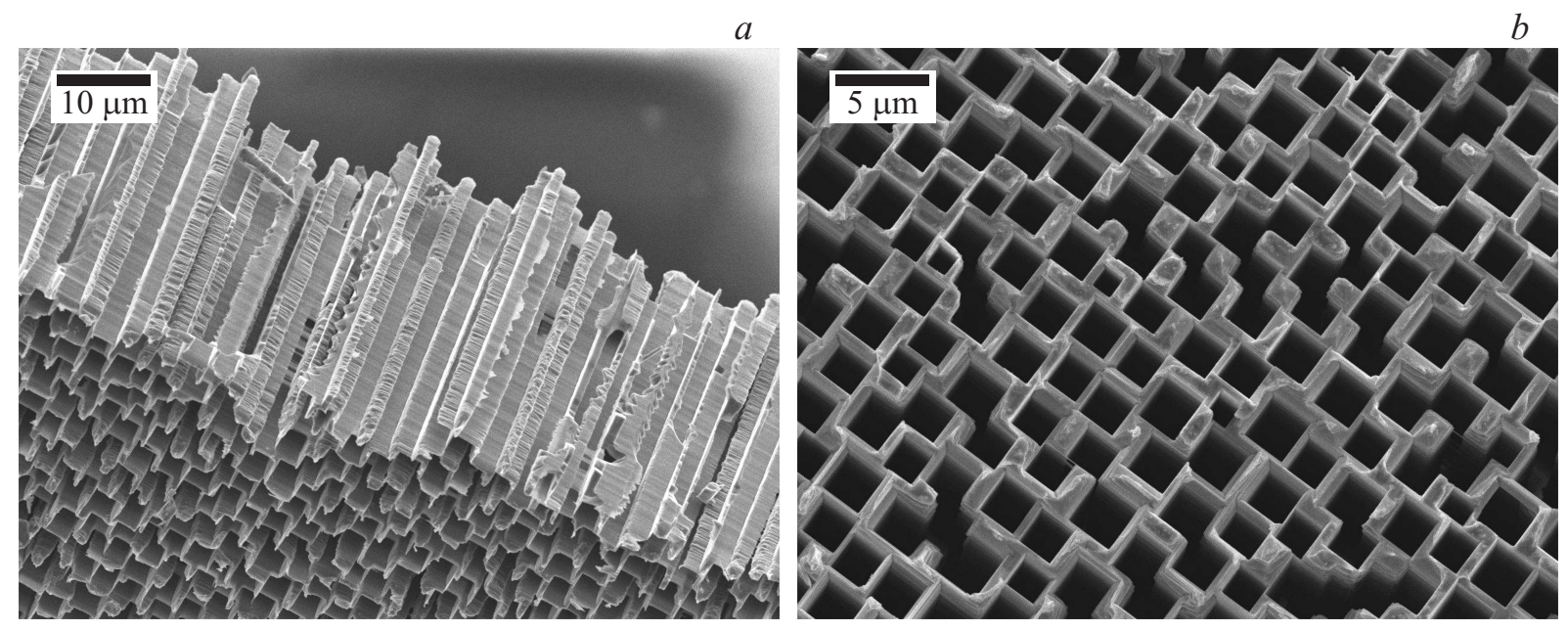

Рис. 11. SEM-микрофотографии мембраны после отделения в щелочном растворе: $a$ - поперечное сечение, вид под углом к поверхности; $b$ - обратная сторона.

видно из рис. $10, c$ и $d$, плавное изменение тока приводит к более ровным краям пор. В дальнейшем при изготовлении мембран был сделан выбор в пользу режима плавного нарастания $j$.

Пористость мембран составляла $\sim 45 \%$, соответствующая ей средняя толщина стенки $w \sim 1$ мкм, в то время как оптимальной для анодных $\mathrm{Si}$-структур следует считать $w=0.3-0.5$ мкм $[5,6]$. В случае неупорядоченных пор, полученных без применения фотолитографии, существует разброс толщины стенок. При заведомо большой плотности тока отделение мембраны происходит прямо в ячейке для анодирования, что неудобно. Для надежного отделения мембраны после извлечения из ячейки мы использовали меньший ток в сочетании с обработкой после анодирования в щелочном растворе, которая преследовала две цели: увеличить пористость мембраны (шейпинг макропор) и отделить пористый слой от подложки. Для этого применялся анизотропный травитель: $12.3 \%$-й водный раствор КОН с добавлением изопропилового спирта [21]. Процесс проводился при комнатной температуре в течение 30-40 мин. Типичная структура мембраны показана на рис. 11. В результате обработки после анодирования ширина макропор возрастала, а их сечение становилось квадратным (рис. 11, b).
Перед повторным анодированием в углублении, образовавшемся после отделения первой мембраны, располагали уплотнительное кольцо. Всего в описываемом эксперименте было отделено последовательно 4 мембраны. Параметры полученных мембран практически одинаковы (см. табл. 2), кроме плотности пор на поверхности первой мембраны, на лицевой стороне которой плотность пор была выше. Последующие мембраны имеют фиксированную плотность пор, повторяющую плотность на обратной стороне первой мембраны.

Пористость отделенных мембран определяли из их массы $m_{\text {mem }}$, толщины $L_{\text {mem }}$ и площади $S_{\text {mem }}$ :

$$
p_{\mathrm{mem}}=1-\frac{m_{\mathrm{mem}}}{\rho_{\mathrm{Si}} L_{\mathrm{mem}} S_{\mathrm{mem}}} .
$$

По SEM-микрофотографиям обратной стороны были подсчитаны плотность пор $N_{\text {back }}$ и пористость $p_{\text {back }}$ с помощью программы ImageJ, имеющейся в свободном доступе. Данная программа предназначена для обработки изображений и использует разницу в значениях интенсивности объектов (в нашем случае пор) на их краях. Выбирая пороговое значение интенсивности, можно определить границы пор. На SEM-изображении наших образцов глубокие поры выглядят черными, а более

Таблица 2. Параметры мембран, отделенных от одной подложки в щелочном растворе

\begin{tabular}{l|c|c}
\hline Параметр (среднее значение) & Обозначение & 3начение \\
\hline Толщина & и единица измерения $^{\text {mem, мкм }}$ & $49.8 \pm 2.2$ \\
Гравиметрическая пористость & $p_{\text {mem }, \%}$ & $71.1 \pm 2.3$ \\
Плотность пор & $N_{\text {back, } \text { мкм }^{-2}}$ & $0.149 \pm 0.055$ \\
Расстояние между порами & $a$, мкм & $2.79 \pm 0.10$ \\
Сторона квадрата в сечении поры & $b$, мкм & $2.19 \pm 0.07$ \\
Толщина стенки & $w$, мкм & $0.60 \pm 0.06$ \\
Пористость в глубине мембраны & $p_{\text {back } \%}$ & $48.3 \pm 1.9$
\end{tabular}


$a$

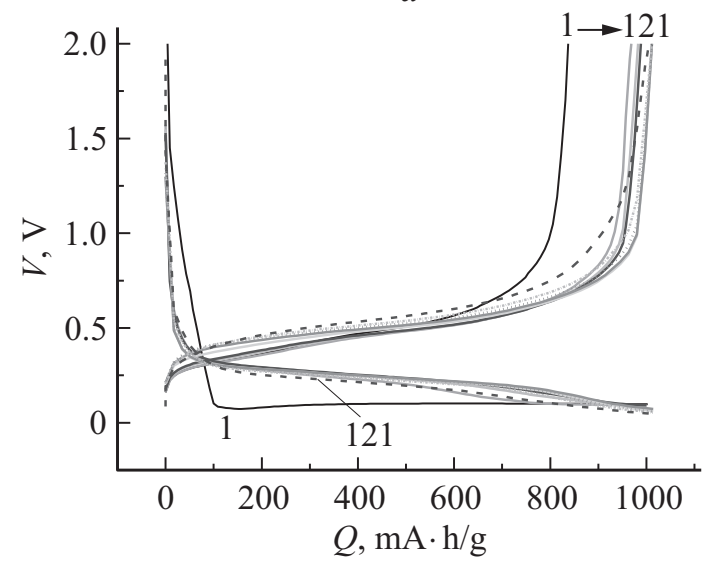

$b$

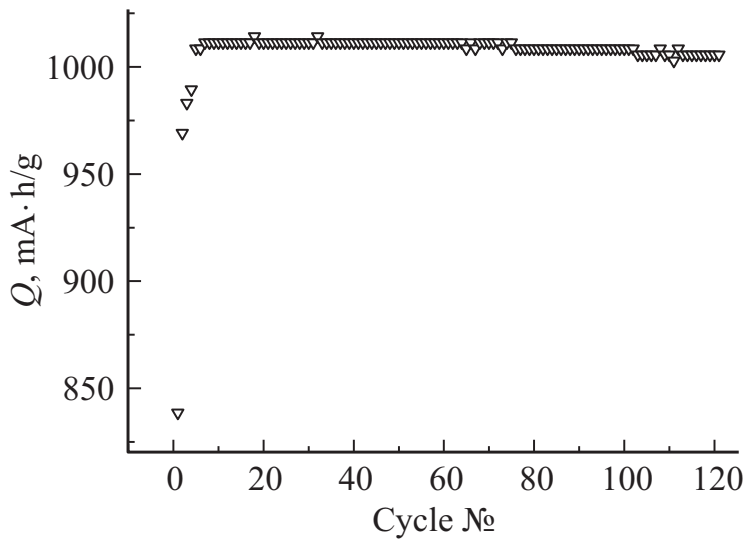

Рис. 12. Электрохимические характеристики анода, изготовленного из кремниевой мембраны, полученные при токе на единицу массы $j_{m}=200 \mathrm{MA} / г: a-$ зарядно-разрядные кривые (числа около кривых соответствуют номерам циклов), $b-$ зависимость разрядной емкости от числа циклов.

мелкие углубления светлее (разные градации серого). В зависимости от того, что принять за порог, можно подсчитать пористость либо вблизи поверхности, либо в глубинных слоях пористой структуры. Как и в предыдущем разделе, с учетом гексагональной симметрии в расположении макропор из $N_{\text {back }}$ было рассчитано среднее расстояние между порами $a$. Его величина немного превосходит найденную для того же тока в разд. 2 по плотности пор в поперечном сечении. Причиной расхождения, по-видимому, является слияние после шейпинга некоторых пор, что воспринимается программой ImageJ как уменьшение их числа. Наши мембраны характеризуются переменной пористостью: у внешних поверхностей она выше, а в глубинных областях ниже. Таким образом, гравиметрическая пористость $p_{\text {mem }}$ и вычисленные из нее $b=\sqrt{p_{\text {mem }} / N}, w=a-b$ отражают средние по глубине и площади величины. Пористость $p_{\text {back }}$ характеризует только внутренние слои мембраны. Неудивительно, что $p_{\text {back }}<p_{\text {mem }}$.

\section{4. Изготовление и испытание анодов}

Для нанесения электрического контакта на поверхность мембран сначала проводили вакуумное напыление меди с подслоем хрома (общая толщина пленки $\sim 1$ мкм). Заметим, что при необходимости после этой операции возможно дополнительное увеличение пористости с помощью шейпинга, так как пленка меди увеличивает прочность мембраны, оставляя поры открытыми с двух сторон. Затем осуществлялось гальваническое осаждение меди в электролите на основе медного купороса с добавлением небольших количеств серной кислоты и этанола. Плотность тока осаждения составляла $10 \mathrm{MA} / \mathrm{cm}^{2}$, время осаждения 375 мин. Толщина слоя осажденной меди была $\sim 20$ мкм. Из полученных мембран было вырезано по одному образцу площадью $0.11-0.15 \mathrm{~cm}^{2}$, и проведены их электрические испытания в качестве анодов. Для испытаний использовались двухэлектродные дисковые ячейки CR2032 с литиевым противоэлектродом. Электролит марки ТC-E810 (Tinci)

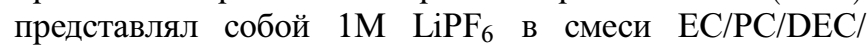
EMC/PA (этиленкарбонат/пропиленкарбонат/диэтилкарбонат/этилметилкарбонат/пропилацетат). Циклические ресурсные испытания в гальваностатическом режиме проводили с использованием зарядно-разрядного стенда CT3008W-5V10mA (Neware).

Режим электрических испытаний предусматривал следующие ограничения: 1) удельная зарядная емкость $Q=1000$ мА · ч г, 2) диапазон изменения напряжения $V=10-2000$ мВ. Время полуцикла составляло 5 ч. Первые 4 цикла проводились при токе, который был в 2 раза меньше номинального, соответственно продолжительность цикла увеличивалась в 2 раза. Такой прием позволяет избежать возникновения избыточных механических напряжений внутри структуры анода. Все четыре образца показали практически одинаковые электрохимические характеристики. Типичные зарядно-разрядные кривые и зависимость разрядной емкости от номера цикла приведены на рис. 12, $a$ и $b$. Как обычно для кристаллического кремния, первая зарядная кривая отличается от последующих, что связано с аморфизацией, происходящей при литировании $[10,22]$. Кулоновская эффективность для большинства циклов близка к 100\%, за исключением начальных (в основном первого), где необратимые потери заряда связаны с формированием на поверхности электрода пленки твердофазного электролита (SEI). Peзультаты проведенных испытаний показали, что после 120 циклов электрохимические характеристики анодов не обнаруживают признаков деградации.

Для оценки быстродействия было использовано 2 сценария: при первом варьировалась скорость циклирования, т.е. одновременно изменялись как ток заряда, так и ток разряда (внедрения и экстракции лития), при втором сценарии ток заряда сохранялся неизменным, а варьировался только ток разряда. Для этого один из образцов после 75 циклов ресурсных испытаний 

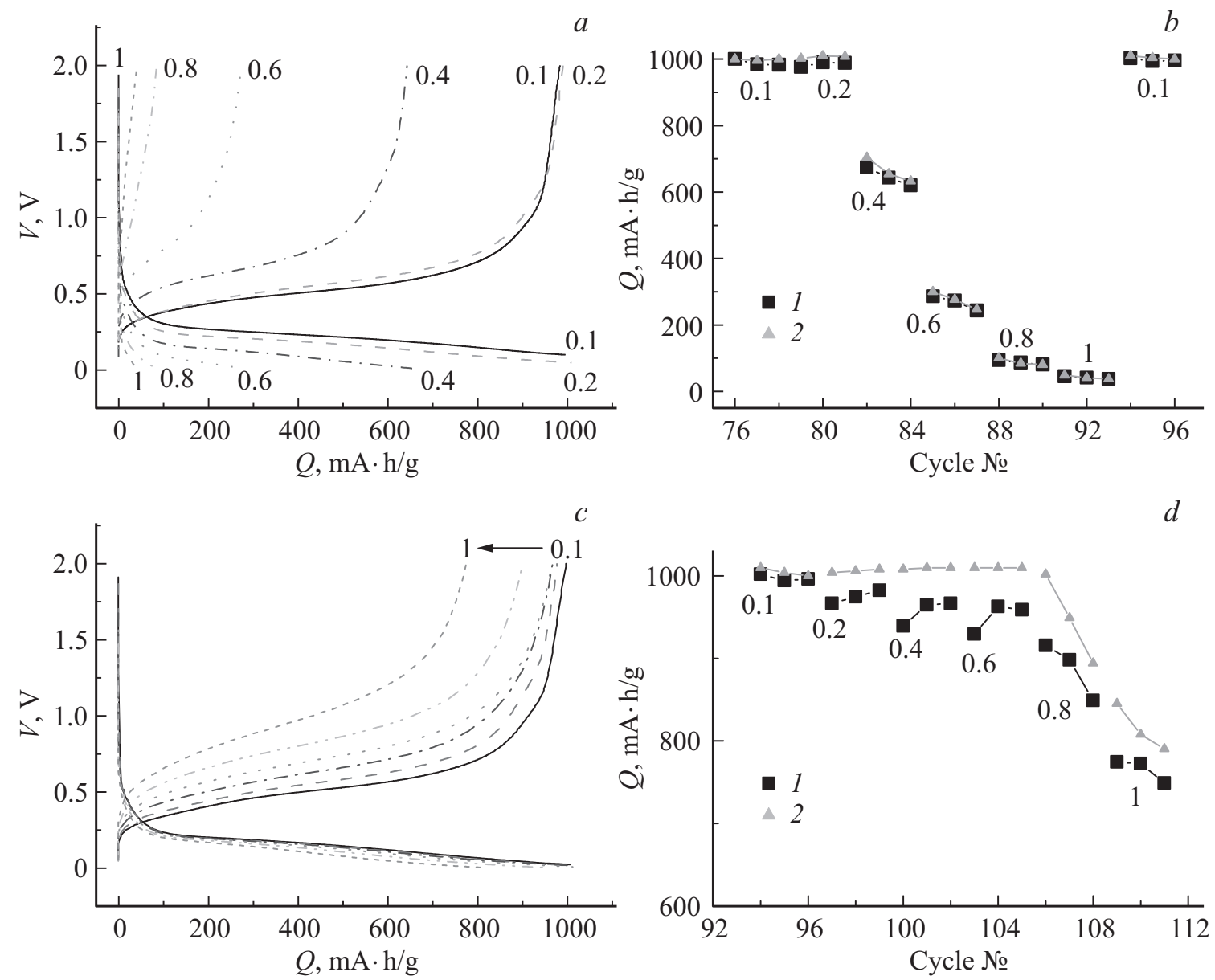

Рис. 13. Электрохимические характеристики анода при разных режимах циклирования: $a, c$ - данные, полученные при изменении времени заряда и разряда, при $0.1,0.2,0.4,0.6,0.8$ и $1 \mathrm{~A} / \Gamma ; b, d$ - данные, полученные при сохранении неизменного тока заряда $(0.2 \mathrm{~A} / \Gamma)$ и варьировании только тока разряда. $b, d: 1-$ разрядная емкость, 2 - зарядная. Числа около кривых указывают ток в $\mathrm{A} / \Gamma$.

подвергался тестированию последовательно по первому и второму сценариям. При каждом токе проводилось по 3 цикла внедрения и экстракции лития. На рис. 13, a показано, как меняются при этом зарядно-разрядные кривые кремниевой мембраны (приведено по одной кривой из трех), а на рис. $13, b-$ значения емкости заряда и разряда в зависимости от номера цикла. Из приведенных рисунков можно видеть, что зарядная и разрядная емкости анода уменьшаются с увеличением скорости циклирования. Это объясняется тем, что при заряде большим током в анод не успевает внедриться заданное количество лития, обогащая только приповерхностную область электрода. В результате быстро достигается напряжение 10 мВ, после чего, согласно заданным ограничениям, начинается процесс разряда. При токах 0.1 и $0.2 \mathrm{~A} / \Gamma$ характеристики остаются практически идентичными, а по мере дальнейшего увеличения тока $Q$ сильно падает. Из рис. 13, $b$ видно, что после возврата к малым токам $(0.1 \mathrm{~A} / \Gamma) Q$ анода вновь возвращается к исходному значению. Характеристики, полученные в ходе испытаний по второму сценарию, показаны на рис. $13, c$ и $d$. В этом случае изменения, происходящие при увеличении тока разряда, существенно меньше, чем при испытаниях по первому сценарию, и падение емкости не столь существенно. Причиной снижения зарядной емкости при токах $j_{m} \geq 0.8 \mathrm{~A} / г$ является неполная экстракция лития из электрода во время предыдущего полуцикла, в результате чего дополнительно внедрившийся $\mathrm{Li}$ уменьшает поверхностный потенциал до $10 \mathrm{MB}$, хотя зарядная емкость еще не достигла заданного значения. Из рис. 13, $b$ видно также, что кулоновская эффективность снижается с ростом тока разряда.

\section{5. Заключение}

Проведенные исследования показали, что при анодировании кремниевых подложек $р$-типа проводимости с концентрацией $(0.5-1) \cdot 10^{15} \mathrm{~cm}^{-3}$ в $4 \%$-м растворе $\mathrm{HF}$ в ДМФ можно воспроизводимо получать самоорганизующиеся макропоры с вертикальными стенками. Увеличение плотности тока при электрохимическом травлении в этом электролите приводит к линейному возрастанию числа неупорядоченных макропор на единицу 
поверхности образца. При этом усиливаются эффекты анизотропии, влияющие на морфологию пористого слоя. Немонотонная зависимость пористости от тока при анодировании в режиме постоянного количества электричества объясняется заметной скоростью химического растворения при длительной экспозиции, его скорость оценивается как 16.5 нм/мин. Разработана технология формирования нескольких мембран с пористостью 70\%, последовательно отделяемых от одной подложки. Проведенные электрохимические испытания показали хороший ресурс, высокую кулоновскую эффективность и среднее быстродействие исследованных структур. Таким образом, технология изготовления макропористых кремниевых анодов может быть существенно упрощена за счет применения $p-\mathrm{Si}$, формирования неупорядоченных макропор и многократного использования подложки.

Работа выполнена при финансовой поддержке в рамках гранта РФФИ № 15-08-02805 и с использованием приборной базы ЦКП „Материаловедение и диагностика в передовых технологиях“ ФТИ им. А.Ф. Иоффе.

\section{Список литературы}

[1] M. Ge, X. Fang, J. Rong, C. Zhou. Nanotechnology, 24, 422001 (2013).

[2] N.-Lih Wu. In: Handbook of Porous Silicon, ed. by L. Canham (Switzerland, Springer Intern. Pub., 2014) p. 965.

[3] M.J. Armstrong, C. O’Dwyer, W.J. Macklin, J.D. Holmes. Nano Research, 7 (1), 1 (2014).

[4] E. Quiroga-González, J. Carstensen, H. Föll. Energies, 6 (10), 5145 (2013).

[5] G.V. Li, A.M. Rumyantsev, V.S. Levitskii, E.V. Beregulin, V.V. Zhdanov, E.I. Terukov, E.V. Astrova. Semicond. Sci. Technol., 31, 014008 (2016).

[6] Е.В. Астрова, Г.В. Ли, А.М. Румянцев, В.В. Жданов. ФТП, 50 (2), 279 (2016).

[7] Е.В. Астрова, А.М. Румянцев, Г.В. Ли, А.В. Нащекин, Д.Ю. Казанцев, Б.Я. Бер, В.В. Жданов. ФТП, 50 (7), 979 (2016).

[8] Г.В. Ли, Е.В. Астрова, А.М. Румянцев, В.Б. Воронков, А.В. Парфеньева, В.А. Толмачев, Т.Л. Кулова, А.М. Скундин. Электрохимия, 51 (10), 1020 (2015).

[9] V. Lehmann. Electrochemistry of Silicon (Weinheim, Wiley-VCH, 2002) p. 200.

[10] Е.В. Астрова, Г.В. Ли, А.В. Парфеньева, А.М. Румянцев, В.В. Жданов, С.И. Павлов, В.С. Левицкий, Е.И. Теруков, В.Ю. Давыдов. ЖТФ, 85 (4), 52 (2015).

[11] J.-N. Chazalviel, F. Ozanam. Ordered Porous Nanostructures and Applications, ed. by R.B. Wehrspohn (N. Y., Springer Science + Business Media, Inc., 2005) p. 15.

[12] H. Foll, M. Christophersen, J. Carstensen, G. Haase. Mater. Sci. Eng., R39, 93 (2002).

[13] A. Slimani, A. Iratni, H. Henry, M. Plapp, J.-N. Chazalviel, F. Ozanam, N. Gabouze. Nanoscale Research Lett., 9, 585 (2014).

[14] H. Halimaoui. Properties of Porous Silicon, ed. by L. Canham (London, UK, INSPEC, Institute of Electrical Engineers, 1997) p. 18.

[15] A. Vyatkin, V. Starkov, V. Tzeitlin, H. Presting, J. Konle, U. König. J. Electrochem. Soc., 149, G70 (2002).
[16] S. Lust, C. Lévy-Clément. Phys. Status Solidi A, 182, 17 (2000).

[17] F. Harraz, K. Kamada, K. Kobayashi, T. Sakka, Y. Ogata. J. Electrochem. Soc., 152, C213 (2005).

[18] E. Quiroga-González, E. Ossei-Wusu, J. Carstensen, H. Föll. J. Electrochem. Soc., 158 (11), E119 (2011).

[19] M. Thakur, R. Pernites, N. Nitta, M. Isaacson, S. Sinsabaugh, M. Wong, L.L. Sibani. Chem. Mater., 24, 2998 (2012).

[20] E. Luais, J. Sakai, S. Desplobain, G. Gautier, F. Tran-Van, F. Ghomouss. J. Power Sources, 242, 166 (2013).

[21] Е.В. Астрова, А.В. Парфеньева, Г.В. Ли, Ю.А. Жарова. ФТП, 49 (4), 561 (2015).

[22] U. Kasavajjula, C. Wang, A. Appleby. J. Power Sources, 163, 1003 (2007).

Редактор Л.В. Шаронова

\section{Anodes for Li-ion batteries based on self-organized macropores in $\boldsymbol{p}$-Si}

\author{
N.E. Preobrazhenskiy, E.V. Astrova, S.I. Pavlov, \\ V.B. Voronkov, A.M. Rumyantsev, V.V. Zhdanov \\ loffe Institute, \\ 194021 St. Petersburg, Russia
}

Abstract Practical application of microstructured anodes produced by electrochemical etching of single crystal silicon is limited by their cost. Proposed way will allow to reduce the cost for few reasons: decreasing of requirements to the quality of initial material by replacing of $n-\mathrm{Si}$ for $p$-Si, excluding of operations aimed to form nucleation centers and multiple using of silicon substrate. In this work formation of random macropores in $10-20 \Omega \cdot \mathrm{cm}$ $p$-Si (100) in 4\% hydrfluoric acid in dimethylformamide solution has been studied and the role of chemical etching has been revealed. Dependences on current density of etching rate, porous layer morphology, effective dissolution valence, pore density and average pore diameter have been obtained. Chemical dissolution role in electrolyte has been determined. We have developed technology of $50 \mu \mathrm{m}$ thick porous layers which combines separation of several membranes from the same substrate and porosity enhancement $(\sim 70 \%)$. Electrochemical characteristics of anodes, formed from these membranes, have been investigated. We conducted $120+$ test cycles in the mode of limited charge capacity $1000 \mathrm{~mA} \cdot \mathrm{h} / \mathrm{g}$ under the current $0.2 \mathrm{~A} / \mathrm{g}$. 